\title{
Impact of pharmacist intervention on glycemic control of type 2 diabetes patients in a tertiary care hospital
}

\author{
Kamelia Sadeghi ${ }^{1}$, Karanesh Dass ${ }^{1}$, Shobha Hiremath ${ }^{1}$, and Swapna Bhaskar ${ }^{2}$ \\ ${ }^{1}$ Al-Ameen College of Pharmacy \\ ${ }^{2}$ St. Philomena's Hospital
}

June 22, 2021

\begin{abstract}
Objective: Diabetes is one of the most common chronic disease that requires comparatively more care to achieve optimal therapeutic outcomes. The aim of this study was to study the impact of pharmacist intervention on glycemic control of type 2 diabetes patients in a tertiary care hospital. The objectives were: To assess the parameters of glycemic control namely FBS, PPBS, and HbA1c; To provide patient education to one group of patients while other group of patients get standard care; To assess the impact of the educational intervention on blood sugar levels and HbA1c. Materials and methods: It was hospital based prospective interventional study carried out in the general medicine out-patient department of St. Philomena's hospital, a tertiary care hospital, in Bangalore, India. The patients recruited were divided equally and randomly into control and intervention groups. Patients in the interventional group received patient informational leaflets, and education in addition to standard treatment, while the control group patients received only standard treatment. Parameters of glycemic control namely FBS, PPBS, and HbA1c of the patients were measured at baseline and at the end of the follow up period of 3 months and compared using appropriate statistical tests. Result: 50 patients having HbA1c value of $>8 \%$ were included in the study. FBS, PPBS, and HbA1c values of all patients were measured at baseline and compared to the values obtained at the end of the follow up period, and was found to be statistically significant $(\mathrm{p}<0.05)$. The difference in the baseline and follow up values between the control and intervention groups was also compared and found to be statistically significant $(\mathrm{p}<0.05)$. Conclusion: It was observed from our study that pharmacist led educational intervention program for the management of type 2 diabetes had a positive impact in lowering the levels of glycemic parameter.
\end{abstract}

\section{Hosted file}

Manuscript.docx available at https://authorea.com/users/421013/articles/527189-impact-ofpharmacist-intervention-on-glycemic-control-of-type-2-diabetes-patients-in-a-tertiarycare-hospital 